\title{
Segmental Resection of the Lung
}

National Cancer Institute

\section{Source}

National Cancer Institute. Segmental Resection of the Lung. NCI Thesaurus. Code C136290.

Surgical removal of a section of a lobe of the lung. 